\title{
An Analysis of Schmidt and Stein's Sport Commitment Model and Athlete Profiles
}

\author{
Cristina De Francisco ${ }^{1, *(1)}$, Cynthia Gómez-Guerra ${ }^{2}$, Ángel Vales-Vázquez ${ }^{3}{ }^{(1)}$ and Constantino Arce ${ }^{2}$ \\ 1 Social Department, University of Sevilla, 41018 Seville, Spain \\ 2 Department of Social, Basic and Methodological Psychology, University of Santiago de Compostela, \\ 15782 Santiago de Compostela, Spain; gomezguerra.cynthia@gmail.com (C.G.-G.); \\ constantino.arce@usc.es (C.A.) \\ 3 Department of Physical and Sports Education, University of A Coruña, 15179 A Coruña, Spain; \\ angel.vales@udc.es \\ * Correspondence: cdefrancisco@us.es
}

Citation: De Francisco, C.; Gómez-Guerra, C.; Vales-Vázquez, Á.; Arce, C. An Analysis of Schmidt and Stein's Sport Commitment Model and Athlete Profiles. Sustainability 2022, 14, 1740. https:/ / doi.org/10.3390/su14031740

Academic Editors: Antonio

Hernández-Mendo, Coral Falco, Verónica Morales-Sánchez,

Cristina Menescardi and

Tomas Herrera-Valenzuela

Received: 10 December 2021

Accepted: 26 January 2022

Published: 2 February 2022

Publisher's Note: MDPI stays neutral with regard to jurisdictional claims in published maps and institutional affiliations.

Copyright: (c) 2022 by the authors. Licensee MDPI, Basel, Switzerland. This article is an open access article distributed under the terms and conditions of the Creative Commons Attribution (CC BY) license (https:// creativecommons.org/licenses/by/ $4.0 /)$.

\begin{abstract}
The sport commitment model proposed by Schmidt and Stein is one of the most complete paradigms on the etiology of burnout syndrome. According to this model, the degree of burnout of athletes is related to the nature of their commitment to sporting activity. Based on the Benefits, Costs, Satisfaction, Alternatives, and Investments, three types of athletes are defined: (1) athletes who are fully committed because they enjoy the activity; (2) athletes who are committed because they feel trapped; (3) athletes who are not committed and are at risk of abandonment. Analysis of cluster and analysis of variance were performed using data collected from a sample of 357 athletes. The results were aligned with the Schmidt and Stein model predictions in terms of athlete type and partial scores for each component of the model, although with slight variations. The percentage of athletes correctly classified is $99.35 \%$ for the cluster of committed athletes; $97.35 \%$ for the cluster of entrapped athletes; $96.63 \%$ for the cluster of non-committed athletes at risk of abandonment. In conclusion, the sport commitment model provides a useful approach to explain the etiology of burnout in athletes, helping to understand the psychological keys to the syndrome.
\end{abstract}

Keywords: sport commitment; athlete burnout; entrapment; social exchange theory; sport dropout; love-commitment theory; investment model; sport enjoyment/satisfaction

\section{Introduction}

The sport commitment model [1] is an etiological paradigm of burnout, in which the variable of interest is sport commitment. It differs from the initial approach posited in the sport field, the cognitive-affective stress model [2], which is based on the notion that burnout is a stress response between the demands and resources of the athlete.

Authors of the sport commitment model consider burnout syndrome in athletes according to a combination of five factors: Benefits, Costs, Satisfaction, Alternatives, and Investments. If the Benefits obtained from sport are high, Satisfaction and Investments are also high, while Costs and Alternatives are low, the athlete would generate a high degree of commitment to the sport, based essentially on positive associations. However, if the five factors are reversed, then athletes can experience serious burnout due to entrapment, namely the sensation that there is no way out, and when they do find one, it generally leads to dropping out of the sport. This could be avoided by intervening on the levels of the factors involved in the model so that the athlete does not feel trapped.

The sport commitment model [1] is based on the theory of social exchange [3], although it is necessary to extend it with the commitment model for personal partnership relationships [4] and the investment model [5,6].

It is important to differentiate between abandonment due to burnout and dropout from sporting practices attributable to other causes (such as the appeal of alternative 
activities). In this sense, it is necessary to identify the factors that determine participation and persistence in the various activities [2]. An effective approach in this sense is the theory of social exchange [3], which claims that human behavior is determined by the desire to maximize positive experiences and minimize negative ones. In this sense, participation in certain activities and/or relationships will occur only if the result is considered sufficiently favorable, estimated in accordance with a balance between tangible and intangible Costs and Benefits [2]. In addition, two useful concepts are proposed to explain why some people drop out of an activity they are satisfied with, while others remain, despite their dissatisfaction. These concepts are termed the comparison level and the comparison level for alternatives [3]. The comparison level is a neutral point for an individual on a goodness-badness scale, determined by past results, observation of the results of others, and momentary situations of need. Any results above this level are considered satisfactory and/or pleasurable, and below they reflect unsatisfactory and/or unpleasurable. The comparison level determines how satisfactory an activity is, but not whether the person will continue to practice it. The comparison level for alternatives is the lowest result a person may accept when the activity is assessed with other alternative ones (including nonparticipation). Considering these two terms, dropout due to burnout could be attributable to the increase in Costs induced by stress, whereby a formerly pleasurable activity becomes a cause of stress, leading to several physical, emotional, and behavioral symptoms. In turn, dropout attributable to Attraction to other activities would explain because anticipated results in other activities increase the level of comparison of the alternatives in relation to the results of participation in the current sport; in other words, there is a shift in interests.

However, the theory of social exchange cannot stand alone as a complete theoretical explanation for sport burnout [1]. It fails to distinguish in terms of Benefits, Costs, and Alternatives between abandonment by athletes with burnout and those that remain. Furthermore, this theory does not inherently include a way to delineate between the development of burnout and the occurrence of dropout as a consequence of exposure to stress. Schmidt and Stein attempt to provide an explanation for this by including the love-commitment theory [4] that draws a distinction between commitment and love. Commitment refers merely to stability between the elements in the relationship, while love is a potential element of the commitment that includes a series of impulses or positive forces, which may be both stable and unstable. This conceptualization would allow for commitment without love, without these positive forces. Applying this notion to sport may reveal the existence of a commitment to the sport stemming from the enjoyment obtained from its practice (love in the original theory) or the absence thereof.

Finally, the theoretical approach [1] also includes the investment model [5,6], which considers Investments as the resources contributed to the relationship, which may be lost if this relationship comes to an end. They can be classified under two types; intrinsic resources of an individual nature that correspond to what we put directly into the relationship and extrinsic resources that would be those associated aspects that are achieved through relationships. When the investment model is applied to sport, high Investments explain the decision to continue with an activity when Costs exceed Benefits [1].

The sport commitment model [1] combines all these aspects and considers the degree of commitment of athletes and their underlying causes (Benefits, Costs, Satisfaction, Alternatives, and Investments), classifying them into three categories: (1) athletes whose commitment stems from their enjoyment of the activity; (2) athletes who are committed because they feel trapped by the pressures within their environment (family, friends, coaches, other significant factors); (3) athletes who are not committed and drop out or are at risk of doing so.

Athletes whose commitment stems from enjoyment do not suffer burnout, while athletes who are committed because they feel trapped may experience burnout, as may those who drop out or are at risk of doing so. Table 1 shows the model predictions for each type of athlete in terms of perceived Benefits, Costs, Satisfaction, Alternatives, Investments, and Burnout. 
Table 1. Model predictions for each athlete type.

\begin{tabular}{ccccc}
\hline & \multicolumn{3}{c}{ Athlete Type } \\
\cline { 3 - 5 } & $\begin{array}{c}\text { Committed Because } \\
\text { They Enjoy the } \\
\text { Activity }\end{array}$ & $\begin{array}{c}\text { Committed } \\
\text { Because They Feel } \\
\text { Entrapped }\end{array}$ & $\begin{array}{c}\text { Uncommitted and } \\
\text { at Risk of } \\
\text { Abandonment }\end{array}$ \\
\hline \multirow{6}{*}{ Variable } & Benefits & High & Low & Low \\
& Costs & Low & High & High \\
& Satisfaction & High & Low & Low \\
& Alternatives & Low & Low & High \\
& Investments & High & High & Low \\
& Burnout & Low & High & High \\
\hline
\end{tabular}

This model can be used by researchers and applied psychologists with an interest in social and psychological processes, helping to increase athletes' participation in their sport activity, while at the same time reducing the prevalence of abandonment and burnout.

Very few studies have corroborated this model, which is widely considered to provide a classical explanation for the origin of burnout. The first empirical research based on the sport commitment model, conducted by Raedeke in 1997 [7], laid the foundations for the most widely accepted definition of sport burnout [8]. This study [7] represented a change in direction from previous research that had defined burnout as a simple response to chronic stress (though it keeps in mind that entrapped commitment is not a stress-free cause of burnout). Using a cluster analysis of 236 swimmers, it compared the sport commitment model based on the combination of the variables Enjoyment, Benefits, Costs, personal Investments, and the degree of Attraction of alternative options. It also assessed social constraints, unidimensional identity, and perceived control—key social factors in the etiology of burnout identified in another classic model [9]. However, this study [7] failed to replicate the three profiles; instead, the results produced four clusters: Enthusiastic, Malcontented, Obligated, and Indifferent. The Enthusiastic cluster fits into the description of committed athletes who enjoy their sport practice, as posited in the sport commitment model [1]. Both Malcontented and Obligated athletes displayed entrapment due to their relatively low-perceived control and a high degree of social constraints. The main difference between them is that Obligated athletes failed to produce clear results regarding their Attraction to their sport (with an average degree of Enjoyment and Benefits and moderately high Costs), while Malcontented athletes defined participation in their sport in a significantly negative manner. Lastly, Indifferent athletes fit perfectly with the low commitment profile and risk of abandonment described in the sport commitment model [1].

Years later, this same group of researchers conducted two more studies with the same objective; namely to corroborate the sport commitment model among coaches, but this time including social factors $[10,11]$. In this case, the results effectively replicated the three profiles, although in the first study [10] the authors highlighted the fact that the sample revealed a highly positive vision of their sport and low levels of burnout, and as such, the results were inconclusive. The second study [11] was designed as a follow-up and was conducted a year later. The specific objective was to analyze whether changes in theoretical determinants of commitment were related to changes in the exhaustion dimension of burnout and the level of commitment in a longitudinal study (two measurements taken during the season). This would reveal possible changes over time. Cluster analyses were again used to observe three groups of coaches who shared features that were common to the three theoretical profiles. Over time, almost two-thirds of the coaches fell into the same profile. Furthermore, those who changed their profile during the study did so in a direction that was in line with the changes in their level of commitment, which also affected their exhaustion scores.

Subsequent research moved away from empirical corroboration of the model to focus on the relationship between the variables included in this approach and several supposedly mediating variables, such as control judgment [12]. Considering the most recent of these 
studies [13,14], the results indicate a clear trend: almost 25 years later, there is a lack of in-depth study on the sport commitment model. In the case of the first study cited [13], the objective was to compare and test the relationship between commitment and burnout by testing a new measurement of commitment based on team importance. These authors saw a need to create a specific measurement tool for commitment that considered team importance in team sports. They defined it as "The pride and honor associated with being on a team, often combined with a sense of responsibility and desire to maintain standards" (p. 7). The second study [14] analyzed the fit of perceived fear of failure as a mediating variable in the estimated relationship between sport commitment and the appearance of burnout among young handball players.

Research during this period has focused on using the Sport Commitment Questionnaire (SCQ) [15] to analyze how certain variables mediate between commitment and burnout. However, little or no research has been conducted on the impact of each of these variables on commitment (Benefits, Costs, Satisfaction, Alternatives, and Investments), as in the studies conducted by Raedeke and his team $[7,10,11]$.

One of the most recent explanatory models for burnout [16] considered the crucial role that the concepts of commitment and entrapment play in burnout, as it contributes additional variables to theories based on stress. The aim of this study is therefore to corroborate the classification of athletes proposed by Schmidt and Stein (1991), returning to the origins of their model. Validations of the instruments proposed by Rusbult and colleagues [17,18] will be used to analyze each of the variables that influence commitment (Benefits, Costs, Satisfaction, Alternatives, and Investments), based on a more heterogeneous sample of athletes.

We hypothesize that the predictions given in Table 1 of the sport commitment model [1] for the three profiles will be empirically confirmed with other measurement instruments and a more varied sample of athletes in terms of the type of sport practiced (athletes from various disciplines as opposed to a single sport).

\section{Materials and Methods}

\subsection{Participants}

A total of 357 Spanish federated athletes participated in the study. An intentional sample method was used to select athletes from 11 different sports (swimming, athletics, canoeing/paddling, triathlon, struggle, badminton, soccer, basketball, gymnastics, cycling, hockey), including 222 men and 135 women, whose ages ranged from 18 to 74 years $(\mathrm{M}=25.66$; $\mathrm{SD}=9.49)$. By competition categories, ranging from lowest to highest, 61 competed on a local level, 21 on a provincial level, 104 on a regional level, and 171 on a national or international level. The number of weekly training sessions ranged from 1 to 12 $(\mathrm{M}=4.59 ; \mathrm{SD}=2.48)$, each lasting between 50 and $690 \mathrm{~min}(\mathrm{M}=11.99 ; \mathrm{SD}=41.87)$.

\subsection{Instruments}

Benefits and Costs. Taking the Rusbult and Farrell model as a reference [17], a six-item questionnaire was developed, customized for sport, consisting of three items in Benefits and three in Costs, with satisfactory factorial validity $(\mathrm{GFI}=0.985, \mathrm{TLI}=0.980, \mathrm{CFI}=0.980$, RMSEA $=0.056($ IC 90\%, 0.016, 0.093), SRMR =0.0328) and composite reliability with values of 0.74 for Benefits and 0.69 for Costs. Favorable results were also obtained for measurement invariance in male and female athletes. An example of an item that measured Benefits was "indicate the degree to which good things are present in your sport", while an example of a Cost measuring item was "indicate the degree to which unpleasant aspects are present in your sport". A Likert-type response scale from 1 to 5 was used, where 1 represented hardly ever and 5 almost always.

Satisfaction, Alternatives, and Investments. To measure these variables, the Investment Model Scale (IMS) [18] was adapted to the context of sport. Exploratory and confirmatory factor analyses allow for the creation of a shortened version of the questionnaire comprising 12 items: 3 that measure Satisfaction, 3 Alternatives, 3 Investments, and 3 Commitment (although this latter dimension was not included in this study). The instrument shows 
acceptable goodness of fit indices (GFI $=0.92, \mathrm{TLI}=0.86, \mathrm{CFI}=0.90, \mathrm{RMSEA}=0.087(\mathrm{IC} 90 \%$, $0.074,0.101)$, RMSR $=0.071$ ) and composite reliability with values of 0.69 for Satisfaction, 0.75 for Alternatives, 0.76 for Investments, and 0.81 for Commitment. The evidence for the invariance of the measurement model in male and female athletes was also favorable. An example of an item measuring Satisfaction was "The sport I practice meets all my sporting needs"; an example of an item measuring alternatives was "There are other sports that appeal to me strongly, and which, as an athlete, I can pursue at some stage." In turn, as an example of an item to measure Investments was "I have put a lot of effort into this sport, and I would lose everything if I gave it up"; an item measuring Commitment was "I would like my involvement in this sport to last forever". A Likert-type scale was used for the responses, where 1 strongly disagreed and 5 strongly agreed with the item statement.

Burnout. It was measured using the Spanish adaptation of the Athlete Burnout Questionnaire [19,20], which was drawn up in 2015 by De Francisco [21]. It consists of nine items grouped into three factors (Physical and emotional exhaustion, Reduced sense of accomplishment, and Devaluation of sports practice), with satisfactory validity and Cronbach alpha reliability indices. An example of an item measuring Physical and emotional exhaustion was "Sport has made me feel physically exhausted"; for Reduced sense of accomplishment, "I think I am not performing at my real level in sports"; for Devaluation of sports practice, "I am not as interested in sports as I used to be." Again, a Likert-type response scale was used with five possible answers, where 1 was hardly ever and 5 was almost always.

\subsection{Procedure}

Two methods were used to collect the data. The first began by contacting several sports club presidents/directors to obtain their consent and that of the athletes and coaches, as well as permission to visit their facilities and collect the data in the dressing rooms during a training session. Once there, a standard procedure was followed to ensure that all athletes received the same instructions. The athletes were also asked to give their informed consent, and confidentiality was guaranteed to ensure maximum levels of sincerity in the answers provided. The sample was completed with a second method based on the use of new technologies: Google Forms was used to launch the same questionnaires, encourage participation, and provide the same instructions as in the face-to-face version.

As the study required the collection of personal data, the Ethics Committee of the University where one of the members of the research team was working at the time (Catholic University of Murcia, UCAM) gave its approval for the project, which was registered as TC6/18 under code CE061810.

\subsection{Data Analysis}

A preliminary analysis of the data was performed to detect any possible missing values or outliers for each item in the three questionnaires used for the study. Descriptive statistics (mean, standard deviation, skewness, and kurtosis) were then calculated, and k-means clustering was carried out to test the Schmidt and Stein (1991) athlete-type model [1] based on the degree of commitment of participants, its causes, and consequences. The final stage consisted of an analysis of variance for repeated measures to compare mean scores between the three types of athletes for each of the variables included in the study.

\section{Results}

\subsection{Preliminary Analysis and Descriptive Statistics}

A preliminary analysis was carried out to detect if there was incomplete information or out of range in any of the items of the three questionnaires used, without finding missing or atypical values.

Table 2 shows the descriptive statistics (mean, standard deviation, skewness, and kurtosis) for Benefits, Costs, Satisfaction, Alternatives, Investments, and Burnout total. The most notable feature is that the mean scores range between 4.26 (Benefits) and 2.29 (Burnout). 
All standard deviations are less than 1, and the skewness and kurtosis values are very low, ranging between 0.04 to and 1.16 , in absolute terms.

Table 2. Descriptive statistics.

\begin{tabular}{ccccc}
\hline & Mean & Standard Deviation & Skewness & Kurtosis \\
\hline Benefits & 4.26 & 0.57 & -0.31 & -0.68 \\
Costs & 2.42 & 0.69 & 0.43 & 0.64 \\
Satisfaction & 4.12 & 0.50 & -0.32 & -0.22 \\
Alternatives & 3.03 & 0.87 & -0.04 & -0.43 \\
Investments & 3.26 & 0.76 & -0.34 & -0.33 \\
Burnout & 2.29 & 0.61 & 0.70 & 1.16 \\
\hline
\end{tabular}

\subsection{Cluster Analysis}

Clustering of k-means was used to test Schmidt and Stein's [1] athlete-type model, with the requirement that athletes be grouped into three clusters. The variables used for the classification were Benefits, Costs, Satisfaction, Alternatives, Investments, and total Burnout score. They were all previously converted to z-scores to facilitate the interpretation of the clusters, the distances between the athletes and the respective cluster centers, and the distances between clusters.

Table 3 indicates the standardized mean values in $\mathrm{z}$-scores for each variable in each cluster. Cluster 1 includes those athletes obtaining a below-average score (i.e., with low, negative scores) in Benefits and Satisfaction, and high scores (above average, positive scores) in Costs, Alternatives, Investments, and Burnout. This description coincides with that given by Schmidt and Stein [1] for athletes whose commitment is attributable to their sense of entrapment. The sole exception to this is the score in Alternatives, which should be below average (in other words, negative), but is slightly above average in the sample $(\mathrm{Z}=0.05746)$.

Table 3. Cluster centers for each athlete type, expressed in z-scores.

\begin{tabular}{cccc}
\hline & Cluster 1 & Cluster 2 & Cluster 3 \\
\hline Benefits & -0.57744 & -0.26232 & 0.57159 \\
\hline Costs & 0.88184 & -0.17922 & -0.53998 \\
\hline Satisfaction & -0.03532 & -1.02765 & 0.61581 \\
\hline Alternatives & 0.05746 & 0.67981 & -0.43223 \\
\hline Investments & 0.52309 & -0.91864 & 0.14613 \\
\hline Burnout & 0.71453 & 0.16246 & -0.61420
\end{tabular}

1 = Committed because they feel trapped; 2 = Uncommitted, at risk of abandonment; 3 = Committed because they enjoy the activity.

Cluster 2 corresponds to athletes who scored low (below average, negative) in Benefits, Costs, Satisfaction, and Investments, and high (above average, positive) in Alternatives and Burnout. It is evident that this description matches Schmidt and Stein's [1] definition of athletes who drop out or are at risk of abandonment. Again, there is a single exception; namely, the score corresponding to Costs, which should be above average (i.e., positive), although the result was below average $(-0.17922)$.

Finally, Cluster 3 coincides exactly with the definition of committed athletes who enjoy the activity posited by Schmidt and Stein [1]. The athletes included in this cluster scored above average in Benefits (0.57159), Satisfaction (0.61581), and Investments (0.14613) and below average in Costs (-0.53998), Alternatives (-0.43223), and Burnout $(-0.61420)$.

Table 4 shows the distance matrix between clusters, given in z-scores. All distances exceed the threshold of 1.96, indicating a statistically significant separation between clusters $(p<0.05)$. 
Table 4. Distances between the cluster centers, expressed in z-scores.

\begin{tabular}{cccc}
\hline Cluster & $\mathbf{1}$ & $\mathbf{2}$ & $\mathbf{3}$ \\
\hline 1 & & 2.232 & 2.432 \\
\hline 2 & 2.232 & & 2.550 \\
\hline 3 & 2.432 & 2.550 & \\
\hline
\end{tabular}

Lastly, Figure 1 illustrates the graph for outliers or athletes that do not fit well with the classification drawn up. The horizontal axis represents the three clusters of athletes, and the vertical axis represents the distance between each athlete and the center of his/her cluster. The boxplot indicates the range of distances corresponding to half of the athletes included in the cluster, and the top horizontal line the limit for the distances considered to be normal. In the case of Cluster 1, which includes the "trapped" athletes, the distance between each athlete and the center of the cluster is normal (two standard deviations above the mean), except for three athletes (numbers 39, 230, and 68), who are placed at a considerable distance from the center of the cluster, indicating that they are not a good fit for the model. However, the percentage of outliers in this cluster is very small. This cluster consists of 113 athletes, 110 of whom are a good fit and a mere 3 who are not, accounting for $2.65 \%$ of the total.

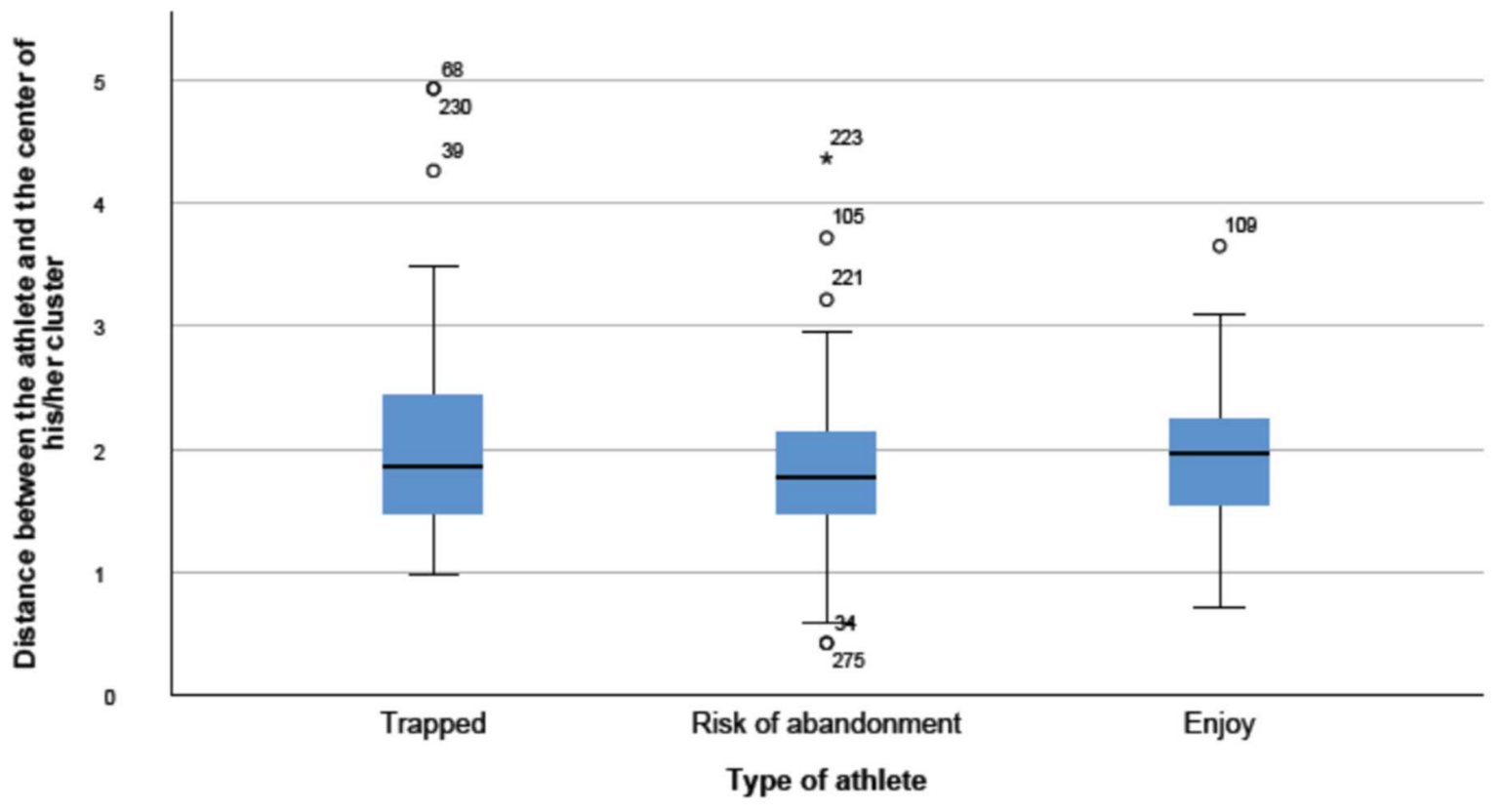

Figure 1. Outliers' graph. Note: ${ }^{\circ}=$ outlier; ${ }^{*}=$ extreme outlier.

Cluster 2, namely athletes at risk of abandonment, is made up of 89 athletes. Only three are positioned at a significant distance from the cluster center-athletes 221, 105, and $223,3.37 \%$ of the total.

Finally, Cluster 3, which comprises committed athletes who enjoy their activity, is made up of 155 athletes, 154 of whom are positioned at normal distances from the center of the cluster $(99.35 \%)$. Only 1 , athlete number 109 , is at a substantial distance, accounting for $0.65 \%$.

\subsection{Analysis of Variance}

As a complement to the cluster analysis, a repeated-measures analysis of variance was performed. The between-subjects factor was the cluster each athlete belonged to, and the within-subjects factor the variables associated with the commitment (Benefits, Costs, Satisfaction, Alternatives, and Investments) and the total Burnout score. 
Table 5 shows the mean scores and standard deviations of each group of athletes for each of the variables studied.

Table 5. Descriptive statistics for the athlete clusters.

\begin{tabular}{cccc}
\hline & Athlete Type & Mean & Standard Deviation \\
\hline \multirow{3}{*}{ Benefits } & Trapped & 3.93 & 0.572 \\
& Risk of abandonment & 4.11 & 0.446 \\
& Enjoy & 4.59 & 0.451 \\
\hline \multirow{3}{*}{ Costs } & Trapped & 3.04 & 0.58 \\
& Risk of abandonment & 2.30 & 0.55 \\
& Enjoy & 2.05 & 0.52 \\
\hline \multirow{3}{*}{ Satisfaction } & Trapped & 4.12 & 0.42 \\
& Risk of abandonment & 3.61 & 0.39 \\
& Enjoy & 4.43 & 0.34 \\
\hline \multirow{3}{*}{ Alternatives } & Trapped & 3.08 & 0.74 \\
& Risk of abandonment & 3.62 & 0.77 \\
& Enjoy & 2.65 & 0.81 \\
\hline \multirow{3}{*}{ Investments } & Trapped & 3.66 & 0.50 \\
& Risk of abandonment & 2.57 & 0.60 \\
& Enjoy & 3.38 & 0.73 \\
\hline \multirow{2}{*}{ Burnout } & Trapped & 2.72 & 0.63 \\
& Risk of abandonment & 2.39 & 0.41 \\
& Enjoy & 1.92 & 0.43 \\
\hline
\end{tabular}

The effect of the between-subjects factor was statistically significant $\left(\mathrm{F}_{2,354}=51.303\right.$, $p<0.001$, partial eta squared $=0.225)$. The same is true for the within-subject factor $\left(\mathrm{F}_{5,1770}=652.912, p<0.001\right.$, partial eta square $\left.=0.648\right)$ and the interaction effect $\left(\mathrm{F}_{10,1770}=81.536\right.$, $p<0.001$, partial eta squared $=0.315$ ).

The line graph in Figure 2 represents the mean scores for each group of athletes ("Trapped" is shown in blue; those at "Risk of abandonment" in red; those who "Enjoy" in green) for each within-subject factor level. All later comparisons made using the Bonferroni test between the mean scores for the three groups at each within-subject factor level were statistically significant $(p<0.001)$.

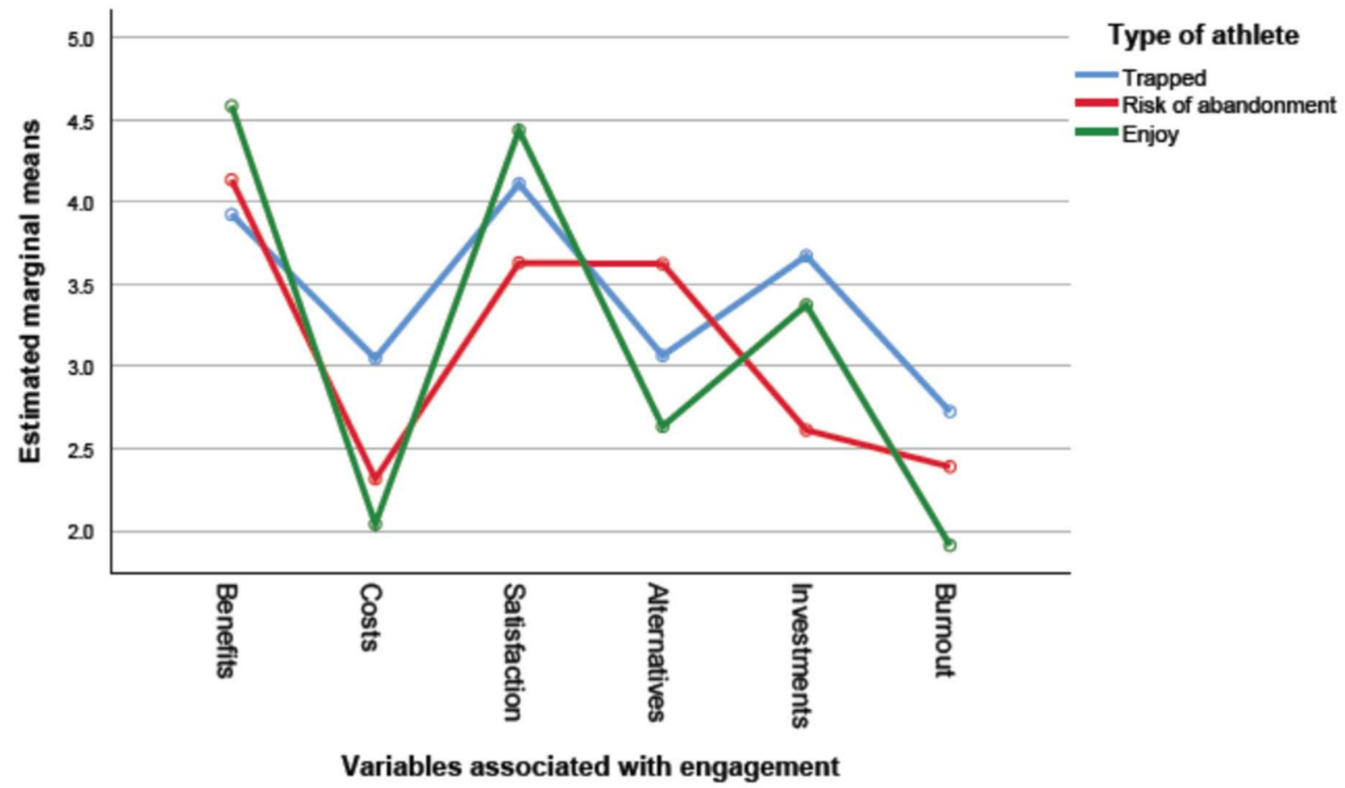

Figure 2. Mean score diagram. 


\section{Discussion}

The objective of this study was to empirically corroborate Schmidt and Stein's sport commitment model in a sample of Spanish athletes by measuring the variables included in the model: Benefits, Costs, Satisfaction, Alternatives, Investments, and Burnout. It was expected that the sport commitment model predictions for the three profiles of athletes would be empirically confirmed.

(a) Athletes whose commitment is attributable to their enjoyment of the sporting activity would obtain higher than average scores in Benefits, Satisfaction, and Investments, and below average for Costs, Alternatives, and Burnout.

(b) Committed athletes who feel trapped would score lower than average in Benefits, Satisfaction and Alternatives, and higher in Costs, Investments, and Burnout.

(c) Athletes who drop out or are at risk of abandonment would obtain lower than average scores in Benefits, Satisfaction, and Investments, and higher ones in Costs, Alternatives, and Burnout.

Following k-mean clustering analyses, the results supported our first prediction and partially corroborated the other two.

Athletes whose commitment stems from their sport activity did indeed display higher than average values in Benefits, Satisfaction, and Investments, and lower than average in the case of Costs, Alternatives, and Burnout. As in other studies, the replication of this profile is straightforward, as observed among swimmers included in the "Enthusiastic" [7] profile, which matches those athletes whose commitment stems from their enjoyment of sport practice, defined in the sport commitment model [1]. In the case of young gymnasts [22], those athletes included in the profile of "Attracted" scored higher for Enjoyment/Satisfaction and Benefits, but lower for Costs and attractive Alternatives.

Regarding those committed athletes who feel trapped (Hypothesis 2), the value was slightly above the mean in Alternatives, even though lower scores were hypothesized. This result agrees with the young gymnasts [22]. Against the predictions in the sport commitment model, gymnasts classified in the entrapment cluster displayed high values in Alternatives, although this is in line with previous results among swimmers included in the "Malcontented" cluster [7]. The high score of gymnasts in Alternatives may be because, although they no longer enjoy such a demanding activity, other activities may appeal to them. This attraction to other activities is perfectly understandable, although they may not be considered feasible due to previous investments [22]. The study also highlights the possible weight of other variables not included in the sport commitment model, such as social constraints or social support. The athletes do not abandon the activity despite their sense of entrapment and the existence of attractive alternatives, as they do not wish to disappoint their parents. This idea is not new; research on swimmers [7], had also considered these values, included in Coakley's [9] classic social model on the etiology of burnout. This model described the syndrome as a social phenomenon generated within the sports context surrounding athletes, characterized by its constrictive and controlling nature. Social structure predisposes to burnout, restricting the development of the identity and autonomy of young athletes outside the sports environment. The author concluded that burnout occurs when young athletes feel unable to claim and build their identity beyond that of the athlete and when their social contexts are organized in a manner that removes their ability to control and make decisions. Namely, identity, control, and so on are the things that lead to burnout (dropout in Coakley's perspective) [9]. Regarding the third hypothesis, athletes who drop out or are at risk of abandonment obtained low scores in Costs, despite the predicted high results. Other studies had also obtained results that differed slightly from the original model, with average rather than high scores $[7,22]$. This cluster represents those athletes who do not feel attracted or trapped by their sport and are highly likely to abandon the sport. The low values for Costs are understandable as they are in a vulnerable position. This vulnerable position is looking for a way out by abandoning what they thought they were doing well, and there, mental health probably takes precedence over the Costs-Benefits balance, and where the former is no longer 
relevant. It is not pertinent because these Costs are not going to be recovered and it is a priority to attend to other issues such as recovery mentally.

Turning to the analysis of variance, where the between-subjects factor is the cluster corresponding to each athlete and the within-subject factor is the variables associated with commitment (Benefits, Costs, Satisfaction, Alternatives, and Investments), and the total Burnout score, the results showed that all effects were statistically significant (betweensubjects, within-subjects, and interaction), thereby underpinning the results obtained from the cluster analysis.

One of the main difficulties of this study is the lack of recent literature on the empirical corroboration of the model. Several searches on a selection of databases such as PsycINFO, Psicodoc, PsycArticles, Psychology Database, CINAHL, PubMed, and SPORTDiscus in the specific fields of Title (ti) and Abstract (ab) produced very few research results. Furthermore, and considering that review of the references of key articles is a recommended search source to locate research that was not detected in the databases, a manual review of the references of the latest studies on this topic was carried out $[13,14,23,24]$, which led to the same conclusion.

However, this inconvenience does not affect the relevance of this study: the results indicate that contrasting and comparing the model in a wider and more heterogeneous sample of athletes than in earlier empirical studies (on swimmers and gymnasts) has contributed to creating a body of knowledge on burnout in athletes. Moreover, in terms of intervention, and as indicated in research with gymnasts [22], a good intervention would be to generate high values of Enjoyment/Satisfaction and Benefits while reducing Costs and attractive Alternatives for the cluster with a low level of commitment. This could allow the recovery of this type of athlete, which could then be included in the profile of athletes whose commitment comes from enjoyment. The results also corroborate the need to consider an integrative model that includes additional variables in the etiology of burnout. As posited in early studies on the origins of this syndrome, stress plays an important role [2,25], and the sport commitment model includes other key aspects. However, there are other variables that should be analyzed in conjunction with those referred to earlier. An effective working framework for this integrating model is the one proposed by Gustafsson [16,24], shown in Figure 3.

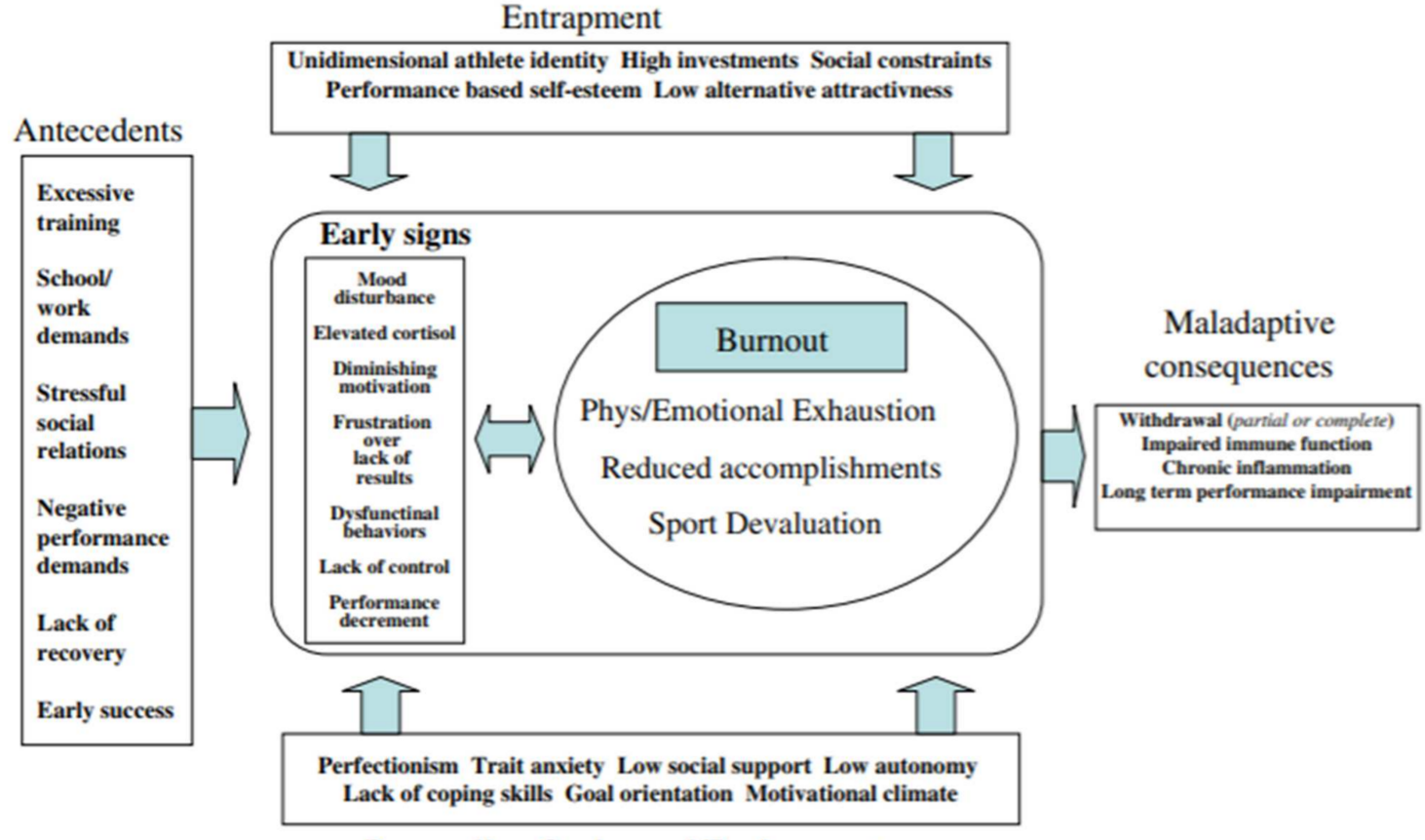

Personality, Coping and Environment

Figure 3. Integrated model of athlete burnout [16] (p. 10). 
The problem lies in determining how to empirically compare and test such a complex model. Future research should continue along these lines, considering how to analyze all these variables involved in the etiology and maintenance of burnout. Perhaps, due to the large number of variables involved, qualitative works that study smaller samples and in greater depth could be an answer to this difficulty.

Finally, as a general conclusion of this study, it provides a useful approach to explain part of the origin of burnout in athletes. Therefore, this model can be included within other broader ones (such as Gustafsson's model). It also enables the detection of athletes who are in a situation of entrapment, being able to intervene on it, both to avoid burnout syndrome and premature withdrawal due to it.

Author Contributions: Conceptualization, C.D.F., C.A., Á.V.-V. and C.G.-G., methodology, C.D.F. and C.A.; formal analysis, C.A.; investigation, C.D.F., C., Á.V.-V. and C.G.-G.; resources, C.D.F. and C.A.; data curation, C.G.-G.; writing-original draft preparation, C.D.F. and C.A.; writing-review and editing, C.D.F., C.A., Á.V.-V. and C.G.-G.; supervision, C.D.F., C.A. and Á.V.-V.; project administration, C.D.F. and C.A.; funding acquisition, C.A. All authors have read and agreed to the published version of the manuscript.

Funding: This research was funded by Xunta de Galicia (Consolidación 2019 GPC GI-1456 Comportamiento Social y Psicometría Aplicada—COSOYPA, Consellería de Educación, Universidade e Formación Profesional), grant number ED431B 2019/0.

Data Availability Statement: Not applicable.

Acknowledgments: The authors thank UCAM for the review carried out by the Ethics Committee.

Conflicts of Interest: The authors declare no conflict of interest.

\section{References}

1. Schmidt, G.W.; Stein, G.L. Sport commitment: A model integrating enjoyment, dropout, and burnout. J. Sport Exerc. Psychol. 1991, 13, 254-265. [CrossRef]

2. Smith, R.E. Toward a cognitive-affective model of athletic burnout. J. Sport Psychol. 1986, 8, 36-50. [CrossRef]

3. Thibaut, J.; Kelley, H. The Social Psychology of Groups, 1st ed.; John Willey and Sons: New York, NY, USA, 1959. [CrossRef]

4. Kelley, H. Love and commitment in close relationships. In Close Relationships, 1st ed.; Kelley, H., Ed.; Freeman and Company: New York, NY, USA, 1983; pp. 265-314.

5. Rusbult, C.E. Commitment and satisfaction in romantic associations: A test of the investment model. J. Experc. Soc. Psychol. 1980, 16, 172-186. [CrossRef]

6. Rusbult, C.E. A longitudinal test of the investment model: The development (and deterioration) of satisfaction and commitment in heterosexual involvements. J. Pers. Soc. Psychol. 1983, 45, 101. [CrossRef]

7. Raedeke, T.D. Is athlete burnout more than just stress? A sport commitment perspective. J. Sport Exerc. Psychol. 1997, 19, 396-417. [CrossRef]

8. Eklund, R.C.; DeFreese, J.D. Athlete burnout: What we know, what we could know, and how we can find out more. Int. J. Appl. Sports Sci. 2015, 27, 63-75.

9. Coakley, J. Burnout Among Adolescent Athletes: A Personal Failure or Social Problem? Soc. Sport J. 1992, 9, 271-285. [CrossRef]

10. Raedeke, T.D.; Granzyk, T.L.; Warren, A. Why coaches experience burnout: A commitment perspective. J. Sport Exerc. Psychol. 2000, 22, 85-105. [CrossRef]

11. Raedeke, T.D. Coach commitment and burnout: A one-year follow-up. J. Appl. Sport Psychol. 2004, 16, 333-349. [CrossRef]

12. Tutte, V.; Suero, M. Compromiso deportivo, juicio de control y burnout en dos equipos deportivos femeninos. Cienc. Psicológ. 2009, 3, 17-28. [CrossRef]

13. Woods, S.; Dunne, S.; McArdle, S.; Gallagher, P. Committed to Burnout: An investigation into the relationship between sport commitment and athlete burnout in Gaelic games players. Int. J. Sport Psychol. 2020, 51, 247-270. [CrossRef]

14. González-Hernández, J.; da Silva, C.M.; Monteiro, D.; Alesi, M.; Gómez-López, M. Effects of commitment on fear of failure and burnout in teen Spanish handball players. Front. Psychol. 2021, 12, 538. [CrossRef] [PubMed]

15. Scanlan, T.K.; Simons, J.P.; Carpenter, P.S.; Schmidt, G.W. The Sport Commitment Model: Measurement development for the young-Sport domain. J. Sport Exerc. Psychol. 1993, 15, 16-38. [CrossRef]

16. Gustafsson, H.; Kenttä, G.; Hassmén, P. Athlete burnout: An integrated model and future research directions. Int. Rev. Sport Exerc. Psychol. 2011, 4, 3-24. [CrossRef]

17. Rusbult, C.E.; Farrell, D. A longitudinal test of the investment model: The impact on job satisfaction, job commitment, and turnover of variations in rewards, costs, alternatives, and investments. J. Appl. Psychol. 1983, 68, 429. [CrossRef] 
18. Rusbult, C.E.; Martz, J.M.; Agnew, C.R. The investment model scale: Measuring commitment level, satisfaction level, quality of alternatives, and investment size. Pers. Relat. 1998, 5, 357-387. [CrossRef]

19. Raedeke, T.D.; Smith, A.L. Development and preliminary validation of an athlete burnout measure. J. Sport Exerc. Psychol. 2001, 23, 281-306. [CrossRef] [PubMed]

20. Raedeke, T.D.; Smith, A.L. The Athlete Burnout Questionnaire Manual, 1st ed.; Fitness Information Technology: Morgantown, WV, USA, 2009.

21. De Francisco, C. Versión reducida del Athlete Burnout Questionnaire (ABQ): Propiedades psicométricas preliminares. Rev. Psicolog. Deport. 2015, 24, 177-183. [CrossRef]

22. Weiss, W.M.; Weiss, M.R. Attraction-and entrapment-based commitment among competitive female gymnasts. J. Sport Exerc. Psychol. 2003, 25, 229-247. [CrossRef]

23. Gustafsson, H.; Madigan, D.J.; Lundkvist, E. Burnout in athletes. In Handbuch Stressregulation and Sport, 1st ed.; Fuchs, R., Gerber, M., Eds.; Springer: Berlin/Heidelberg, Germany, 2018; pp. 489-504. [CrossRef]

24. Gustafsson, H.; DeFreese, J.D.; Madigan, D.J. Athlete burnout: Review and recommendations. Curr. Opin. Psychol. 2017, 16, 109-113. [CrossRef] [PubMed]

25. Silva, J.M. An analysis of the training stress syndrome in competitive athletics. J. Appl. Sport Psychol. 1990, 2, 5-20. [CrossRef] 